\title{
High-Performance Natural Dyes for Cellulosic Fibers: Review - part 2
}

\author{
Nancy S. El-Hawary \\ Dyeing, Printing and Auxiliaries Department, Textile Industries Research Division, \\ National Research Centre, Cairo 12622, Egypt.
}

\begin{abstract}
$\mathbf{T}$ HIS PART is review some fundamentals of technologies, its broad application, and gathering some new researches and studies regarding technological aspects in the extraction of natural dyes and there dyeing process on cellulosic fibers. It focuses on recent developments in the coloration of cellulosic fibers. New technique has been involved in the application of the natural dyes such as Ultrasonic, Microwave, Enzymes treatment, Ultraviolet Radiation (UV) Technology, chitosan and plasma that have the potential to limit the environmental impact and now become accessible due to less use of energy, water as well as a chemical to compare with the conventional methods.
\end{abstract}

\section{Introduction}

In industry textile processing consumes huge amount of energy as in dye fixation and heat setting. Saving time and energy is of immediate interest to textile industry. The introduction of new techniques which will allow less energy to be used is a highly important area of activity to consider [1]. In recent years, many attempts have been made to improve various aspects of dyeing, and new technologies have been, and are being developed to reduce fiber damage, decrease energy consumption and increase productivity. In this part, new technologies that improve the dyeability of proteinous fibers such as ultrasound, ultraviolet, ozone, plasma, gamma irradiation, laser, microwave, e-beam irradiation, ion implantation, and supercritical carbondioxide will be overviewed [2].

\section{High-performance natural dyes for dyeing cellulosic fabrics \\ Mordanting and Dyeing}

Constraints on color productivity and poor stability properties have prompted the search for ideal stones, chemicals that increase the absorption of natural dyes by textile fibers. Different kinds of mordant give different colors even for the same natural pigment. Therefore, the final color, and the characteristics of its brilliance and color not only depend on the dye itself, but also are also gritty by the differentiated focus and skilled operation of the alphabet. Thus, the tart is more important than the dye itself. In addition, the ideal holder for bulk use should produce remarkable color production in low-cost dyeing conditions, without extremely touching the physical properties of fibers or the stability properties of dyes. In addition, it should not cause any harmful effect through processing and dyed textile materials should not have any hazardous effect during use. Mordant can be classified into the following types:

- Metallic mordant

- Alum

- Chrome (potassium dichromate)

- Tin (stannous chloride)

- Copper (cupric sulphate)

- Iron (ferrous sulphate)

- Tannins

Since cotton fibers can be dyed in a coordinated fashion of cellulose molecules with natural dyes with the help of various metal ions, it is important to determine whether this process can also be used to apply pigment dyes to cotton. Currently, a great quantity of researchers around the world are working on natural color improvements. Afterwards extraction processing, the next step is to apply natural colorings to textiles with or short of the help of mordant. From the beginning of its use to the dyeing of textiles through traditional methods to the innovative and sophisticated methods that have been trending lately, natural colors are gaining their spaces in textile coloring and jobs [3]. 


\section{Different mordanting methods and application of natural dyes}

Mordanting can be achieved by pre-mordanting (before dyeing), simultaneously mordanting and dyeing or it may be a post mordanting system (after dyeing). Different types of mordant can be applied on the textile to increase the absorption of coloring from natural dyes. Intensive work has been described, Ding et al. [4] for dyeing textiles with natural dyes that adopt a specific mordanting system for certain textile materials. Sarkar et al. [5], reports the results of properties and fastness characteristics of flax fabric dyed with four natural colors of plant origin and insects. The colors were of plant origin of red sandalwood. Pre-mordanting investigation increased color strength and fastness properties for cochineal dyed fabrics. On the other hand, Umbreen et al. study the properties of natural (Turmeric) dyes using alum and iron as a mordant in different mordanting method on cotton fabrics and it can see the high of the color strength of mordanted cotton fabric than the other fabric that not used the mordant. Mordants play very important role in imparting color to the fabric. The mordants used in combination in different ratios gave varying shades [6]. Similarly, Sofyan et al. study the effect of type and method of mordant towards cotton fabric dyeing quality using jengkol (Archidendron jiringa) pod waste and the results show that the type of mordant affected the intensity and color strength of the fabric. The use of FeSO4 mordant produced the highest color darkness and difference for all mordant methods which can be seen from the value of K/S and dE. From the treatment of mordant type and method, the lowest color darkness was obtained in $\mathrm{CaO}$ mordant with the simultaneous method [7]. Kulkarni et al. performed to used (Punica granatum) pomegranate peel as a natural dyes for dyeing cotton fabric using two mordants-copper sulphate and ferrous sulphate with a different method of mordanting and the fabrics dyed gave different shades of yellow, brown and black with good fastness properties [8].

\section{Technology used in dyeing process \\ Ultrasonic Technology}

Nowadays, ultrasonic energy technology is exploited in textiles dyeing because ultrasound has some great advantages over traditional dyeing, e.g., for example, low temperature and dyeing time, low amount of dye and electrolyte required. Kamel et al. have disclosed, that when the Cotton fabrics were dyed with natural coloring matter using a traditional heating method in comparison with a power ultrasonic method, extracted from Crocus sativus (saffron) the better yields deep color in shorter time. This case once again highlights the effect of the ultrasonic energy on the susceptibility of cotton fabrics dyed with Crocus sativus (flowers) [9]. The penetration rate of the dye within the fiber is also accelerated by piercing the insulating layer covering the fiber and accelerating the raction or chemical reaction between the dye and fiber. Relevantly, cotton was dyed with Eclipta natural dye using both conventional and ultrasonic dyeing, and Vankar $e t$ al. reported the efficacy of ultrasonic dyeing [10] to be higher by $7-9 \%$ than that of the traditional method. Similarly, Symplocos spicata was found to have good agricultural potential as a dye factory. Red metal is found when used in conjunction with Symplocos spicata to enhance the dyeability of the cotton fabric and the properties of hardness. Improved dye absorption was better than nonbusy fabrics. The replacement of the traditional bathroom with an ultrasonic bath make the dyeing process energy-saving and economical with better dye depletion. Even the properties of the withstand in the case of ultrasonic dyeing show good results [11].

\section{Microwave Technology}

The high energy consumption in textile manufactures give evolution to a series of severe environmental problem, which is prominent in the conventional dyeing process, so the synthesize and application of natural and synthetic dyes for various fabrics with microwave technology is the resource-saving and environment friendly method, wherefore the researches are undertaken with a view to establish a green strategy for dyeing with this technology. Huang et al. choose cotton bleaching fabric dyeing with microwave method compared with the conventional method. The results showed that the using microwave technology for cotton fabric solid color processing, with the increase of microwave radiation power, the amount of color cotton rose, and when microwave radiation power is controlled in $700 \mathrm{w}$, the effect is the best than the conventional method [12]. On the other hand, Yavas et al. Nettle Bio (cotton) was used for environmentally friendly dyeing, Madder (Rubia tinctorum L.), using alternative dyeing methods such as microwave energy. Dyeing was performed using the traditional exhaust method, the method of using the microwave using green tea and alum as a mordant. Color and fastness properties and FTIR-ATR spectra were examined for dyed biophysics. Although the strength of dye 
with the help of microwave was not as high as in traditional dyeing, the use of microwave energy in dyeing is important in terms of shortening process time. All dyed nettle fabrics showed a very high, commercially acceptable, dehydration, alkaline, acidic acid and water stability properties. Generally, the microwave dyeing method has led to a lighter appearance compared to conventional dyeing method [13].

\section{Ultraviolet Radiation (UV) Technology}

There are several types of radiations, e.g. ultraviolet (UV) and visible. Use UV to modify the texture surface while leaving loose tissue unaffected. Either the surface fibers must be absorbed directly or the photoinitiator should be applied appropriately for the production of large numbers of high-reaction free radicals when the surface of the fabric is exposed to ultraviolet radiation. Surface modification is particularly useful for natural fibers such as wool and cotton, where fiber engineering and fabric properties, now common in synthetics [14]. The treatment of fibers with UV radiations affects the coloration. The photo modification of the fibers allows more dye or pigment to fix on fabric under the normal conditions (e.g. lower temperature), thereby increasing the wettability of hydrophobic fibers to improve depth of shade in printing. The benefits of this technique are good energy saving (low-temperature operation), low environmental impact, simple, economical processing speed and high. The dyes absorb the electromagnetic radiation of the variable wavelength in the visible range of spectrum. The human eye detects the visible radiation only for the relevant harmonizing colors [15].

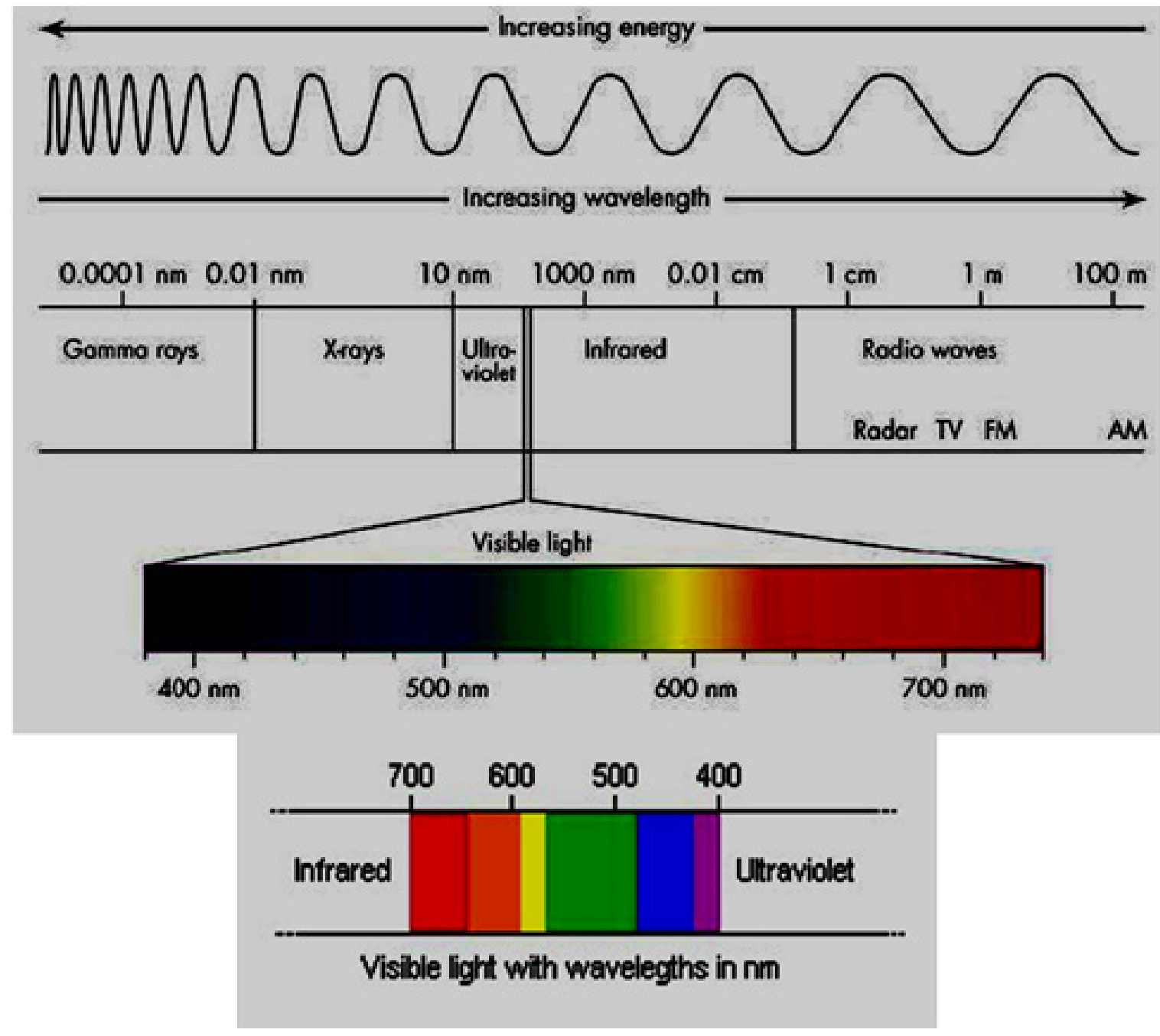

Fig. 1. Regions of electromagnetic spectrum. 
Iqbal et al. Undertaken to extract coloring component from henna and to study its dyeing effect on cotton fabric before and after being exposed to UV radiation. Attempts have also been made to improve the color strength of dye on cotton fabric by using extracts of irradiated henna powder and to improve the color fastness properties of dyed fabrics using irradiated cotton fabric and the result shows that irradiated fabrics dyed with the extracts of henna powder show better color strength than that of non-irradiated fabric dyed with the extract of henna powder. Industrial, This technique used not only to improves the color strength but also enhances the color fastness properties of the irradiated fabric dyed with extracts plane powder [16]. Adeel et al. and Afifah et al. studied the extract (Curcuma longa L.) as a natural dye, that is produced by using different concentrations of turmeric powder, in order to enhance color fastness properties. UV irradiation has not only increased the dye uptake capability of cotton fabric using a little concentration of extracted dye, but also decreased the mordant concentration with admitted lab values and fastness properties. It is detected that UV irradiation can also be employed to other dyeproducing plants for the enhancement of color strength and color fastness properties[17-18].

\section{plasma Technique}

Plasma is the fourth state of matter, after solids, liquids and gases, Sir William Crooke proposed this fourth state for the first time in 1879 . The word plasma originally comes from a Greek term that means something component, beat, and particle, originally used by Irving Langmuir in 1929. There are many uses of plasma technology in various fields such as electrical, medical, mechanical and automotive. Plasma technology is gradually replaced by chemical methods in textiles treatment of. Low-temperature plasma is widely used in modifying the non - destructive surface of textiles where a wide range of properties can be obtained [19]. The plasma technology, which stimulates large surface adjustments and degreasing, removes the natural or synthetic pigments and dyes in textile fibers, increasing the dyeing rate of textile polymers to improve the dispersion of dyes molecules to fibers, enhancing color intensity and washing the stability of many fabrics such as cotton, polyamide, polyester, silk and wool. The higher dye depletion provided by the plasma application improves the uniformity of dyeing to achieve higher levels of strength and reduces the amount of dyes and water required for the desired shade [20]. Chinnammal et al. study the effect of Plasma treatment on plain woven cotton fabric. Cotton fabrics dyed with Marigold Flowers were treated as a natural dye fabric with oxygen and argon gases.T he effect of plasma ttreatment on absorption, weight of the tissue, tensile strength, elongation, thickness, hardness, grease recovery, corrosion resistance and paganity was studied and compared with gray tissue. Plasma treatment after dyeing was apparently performed to improve tissue properties better than before dyeing [21]. Chen et al. Low-temperature microwave plasma is used to treat cotton fabric prior to skin grafting and onion pulp extracts in order to transfer antimicrobial properties to cotton fabrics. It has been discussed that functional groups produced on the upper surface after lowtemperature plasma treatment greatly increase the water-loving nature of the water, thus improving the yield of the vaccine for both skin extracts and bulb [22].

\section{Chitosan Technique}

Chitosan is a linear polysaccharide produced commercially by deacetylation of chitin, the structural element in crustaceans such as crabs and shrimp and fungal cell walls. It has been widely used in various industries because of its multifunctional characteristics. Chitosan is also widely used in the manufacture textile such as dyeing, finishing and printing. In addition to its antimicrobial activity, chitosan has some important advantages such as non-toxicity, biocompatibility and biodegradability. Adsorption and thermodynamic studies of lac dyeing on cotton presets with chitosan were investigated by Rattanaphani et al. Under the conditions of $\mathrm{pH}$ dyeing 3.0, the ratio of substances to liquor (MLR) is 1: 100 and a contact time of 3 hours [23]. The results show that pre-treatment of cotton with chitosan significantly improved the absorption of pigment on cotton and decreased pigment absorption from cotton compared with results in the absence of chitosan. In a similar work, Kavitha et al. Cotton that has been pretreated with chitosan and then dyed with turmeric was used to study its effects on yarn properties. it may be noted that the value of $\mathrm{K} / \mathrm{S}$ cotton fabric coated with chitosan is higher than that not treated. With increased concentration of chitosan also increases absorption of dye [24].

On other work, Verma et al. biopolymer (chitosan) were taken for the pre-treatment of cotton fabric for improving the dye uptake of 
natural dyes and comparison was made with aluminum potassium sulphate (alum) on the basis of color properties of dyed fabrics. Standardization of chitosan treatment and dyeing process for onion skin dye was done. It was found that the chitosan treated onion skin dyed fabric showed higher dye absorption (66.17\%), color strength (16.52) than alum-treated dyed fabric $(55.98 \%, 12.21 \mathrm{k} / \mathrm{s})$ respectively. Thus it is concluded that chitosan treatment enhanced the color properties of cotton fabric without using any harsh chemicals and capable enough to replace use of salt and alkali used as mordant in dyeing of cotton [25].

\section{Bio-Technology (Enzyme Treatment)}

Enzyme treatment has also been used as a sustainable and environmentally friendly way to colorize textiles and their functions. Three enzymes called protease-amylase, diasterase and lipase were combined with tannic acid as a pretreatment on cotton and silk, dyed with natural dyes to evaluate the effect of enzymatic treatment on color properties. An enzymatic treatment was found to give cotton and other kinetic media the rapid absorption speed of adsorption and total adsorption higher than the untreated samples. Indigo dye has poor substantivity for cellulose and hence, it mostly remains at the surface of the fiber after dyeing and as such is called ring dyed. Such ring-dyed materials are subjected to treatment with stone or enzymes, which remove dyes randomly from the abraded portions of the fabric exposing white surfaces. This popular style is utilized in "faded jeans". Microscopy reveals that for indigo dyeing, the extent of the penetration of the colorant into the cross-section of the cotton yarn depends on the $\mathrm{pH}$ of the bath. When the $\mathrm{pH}$ of the dyebath is decreased from 13 to 11 , the yarn progressively becomes ring dyed. Associated with the increasing ring dyeing, more color yield is obtained making the washdown process easier. The highest color yield was observed within the $\mathrm{pH}$ range of 10.8-11.2. Denim garments are made from warp face cotton fabric in which warp yarns are dyed with indigo dyes. These garments are subjected to a wash treatment to give them a worn look. In the traditional stonewashing process, the blue denim is faded by the abrasive action of pumice stones. Cellulases were first introduced in the $1980 \mathrm{~s}$ and nowadays more than $80 \%$ of denim finishers use cellulases or a combination of stones and cellulases to create the worn look on denim. Cellulases work by loosening the indigo dye on the denim in a process known as "biostoning". This treatment can be applied to knit and woven cellulosic fabrics such as cotton, viscose, linen, and their blends. An enzymatic stone-wash process requires equipment with sufficient shear forces and mixing, such as a drum washer. The conventional denim wash process consists of treatment with pumice stones. About $1 \mathrm{~kg}$ stone is required for $1 \mathrm{~kg}$ of denim fabric. A large amount of pumice sludge is produced in this process. For example, a denim finisher processing 100,000 garments a week with stones typically generates 18 tons of sludge [26]. This may block drains so it needs to be filtered out of wastewater. An environmental assessment was performed on jeans, the biostoning process producesvery little sludge and is proved to be more environmentally friendly than the traditional stoning process using pumice. Often irreversible inactivation of the enzyme at the end of the application is beneficial because ongoing enzymatic action may lead to undesired effects such as extended tensile loss and over-performance in the case of cellulase application. Inactivation of the enzyme can be easily realized by shifting the $\mathrm{pH}$ (above 10 for $5-10 \mathrm{~min}$ ) and temperature (above $80^{\circ} \mathrm{C}$ ) to extreme values for a relatively short period. More recently, some authors showed that laccase (with and without using a mediator) is an effective agent for stonewashing effects of denim fabric.

Sricharussina et al. used in the experimental work, pineapple fiber and fiber have been poured with the naturally happening pectinase and cellulase enzymes (separately) and dyed with a selection of 5 natural dyes. Morphological profiles, tensile tests, weight loss, dye absorption, color measurements, and light stability tests were performed [27]. Comparing these results with those of dried fiber in $\mathrm{NaOH}$ (with and without inorganic mordant) shows that enzymes lead to higher dye exhaustion, comparable or greater tensile strength, lighter colors, but similar light fastness. Enzyme-based scouring can therefore successfully prepare pineapple fibers for dyeing using natural material without resorting to potentially poisonous toxic premordants.

Vankar et al. research activity focuses on the of enzymes for dyeing in a natural dye, which is mostly aimed at improving the absorption of dye and improving the properties of stability. Dyeing with natural dyes such as Acacia catechu and (Tectona grandis) shows better and faster dye absorption after enzyme pretreatment such as protease and amylase, lipase and diasterase on cotton fabric [28]. The role of pre-treatment of

J. Text. Color. Polym. Sci. Vol. 17, No.2 (2020) 
the enzyme is primarily to improve the absorption of these dyes on the cotton fabric, adherence, and viability, thus completely replacing the mineral stones with the enzyme to adhere to the natural dyes on the cotton. Enzymes are made up of dye uptake and also appear to produce better dispersion of dye in the tissue. It was observed that enzymes not only increase the fixation of dye matched to untreated and metallic fabrics, but also affect the properties of stability to a certain extent. Similarly, Vankar et al. the enzyme (protease, amylase and cellulase) is used to treat Cotton dyeing and the dyeing with Bixa Orellana seeds with different mordant in two ways and the result shows that the color strength $(\mathrm{K} / \mathrm{S}$ values) is good especially cotton by cellulase enzyme treatment [29]. Cotton fabrics dyed in one step have improved fastness to washing, alkaline perspiration, dry rubbing and light. However, in the case of dyes in the presence of cellulose, the properties of resilience showed an improvement in one measure in the stability of light from cotton fabrics dyed in the presence of amylase.

\section{Future Prospects and Conclusion}

The availability of natural dyes requirements to be increased in a sustainable manner using by-products and wastes from agriculture and agroprocessing industries and judicious collection of forest produce. The important dye-bearing plants on wastelands and marginal lands thus providing an alternative cash crop to cultivators could supplement this. The development of appropriate profiles and verification protocols for natural dyes would improve consumer confidence in natural dyed fabrics and would benefit producers and users alike. If it is possible to increase the availability of natural pigment by the above measures, the cost of primary dyes can be reduced using natural dyes. In chemistry, application and sustainability, there is a wide scope for adoption of these dyes by small dyeing units because they lack the resources to install and operate expensive processing plants, which are necessary to generate synthetic dyes within regulatory limits. If at any time in the future, the accessibility of natural dyes can be increased to very high levels through biotechnological interventions such as tissue culture or genetic engineering, resulting in the production of large amounts of these dyes by microbes at low cost, then their use can only become sustainable to treat the tissue prevailing. At the level of scientific advances today, natural dyes are a viable option only for small applications, and can complement synthetic dyes as an environmentally friendly option for the environmentally conscious consumer and a means of providing livelihoods for various stakeholders in the natural color value chain.

\section{Reference}

1. Haggag, K., Ragheb, A., Nassar, S. H., Hashem,M. El Sayed, H., and Abd El-Thalouth, I., Microwave Irradiation and its Application in Textile Industries, Published by Science Publishing Group, (2014).

2. Atav, R. The Use of New Technologies in Dyeing of Proteinous Fibers, Eco-Friendly Textile Dyeing and Finishing, (January 16 $6^{\text {th }}$ 2013), Melih Günay, IntechOpen, DOI: 10.5772/53912.

3. Yusuf, M. Shabbir, M. and Mohammad, F. Natural Colorants: Historical, Processing and Sustainable Prospects, Journal of Natural Products and Bioprospecting, 7, pp. 123-145 (2017).

4. Y. Ding and H. S. Freeman, Mordant dye application on cotton: optimization and combination with natural dyes, Coloration Technology, 2, pp. 1-7 (2017).

5. A. K. Sarkar and C. M. Seal, Color Strength and Colorfastness of Flax Fabrics Dyed with Natural Colorants, Clothing and Textiles Research Journal, 21, pp. 162-166 (2007).

6. S. Umbreen, S. Ali, T. Hussain and R. Nawaz, Dyeing Properties of Natural Dyes Extracted from Turmeric and their Comparison with Reactive Dyeing, Research Journal of Textile and Apparel,12, pp. 1-11 (2008).

7. S. Sofyan, F. Failisnur, and S. Silfia, The effect of type and method of mordant towards cotton fabric dyeing quality using jengkol (Archidendron jiringa) pod waste, Jurnal Litbang Industri, 8, pp. 1-9 (2018).

8. S. S. Kulkarni, A. V. Gokhale, U. M. Bodake and G. R. Pathade, Cotton Dyeing with Natural Dye Extracted from Pomegranate (Punica granatum) Peel, Universal Journal of Environmental Research and Technolog, 1, pp. 135-139 (2012).

9. M. M. Kamel, H. M. Helmy, and N. S. El Hawary, some studies on dyeing properties of cotton fabrics with crocu ssativus (saffron) (flowers) using an ultrasonic method, Journal of Natural Fibers, pp. 6151-170 (2009). 
10. P. S. Vankar, R. Shanker and J. Srivastava, Ultrasonic dyeing of cotton fabric with aqueous extract of Eclipta alba, Dyes and Pigments, 72, pp.33-37 (2007).

11. P. S. Vankar, R. Shanker, S. Dixit, D. Mahanta, and S. C. Tiwari, Sonicator Dyeing of Natural Polymers with Symplocos spicata by Metal Chelation, Fibers and Polymers, 9, pp.121-127 (2008).

12. D. Huang, The Application Advantages of Microwave Fixation in Cotton Fabric Dyeing, International Conference on Education Technology, Management and Humanities Science, pp. 535-539 (2015).

13. A. Yavas, O. Avinc, G. Gedik, FIBRES \& TEXTILES in Eastern Europe Ultrasound and Microwave Aided Natural Dyeing of Nettle Bio fibre (Urtica dioica L.) with Madder (Rubia tinctorum L.), 25, pp.111-120 (2017).

14. K. Millington, UV Technology: Applications in the Textile Industry, https://www.fibre2fashion.com/ industry-article/124/uv-technology-applicationsin-the-textile-industry?page $=1$ (2018).

15. I. A. Bhatti, S. Adeel and M. Abbas, Effect of Radiation on Textile Dyeing, textile Dyeing Peter J. Hauser, https://www.intechopen.com/books/ textile-dyeing/effect-of-radiation-on-textile-dyeing (2011).

16. J. Iqbal, I. A. Bhatti and S. Adeel, Effect of UV radiation on dyeing of cotton fabric with extracts of henna leaves, Indian Journal of Fibre \& Textile Research, (33), pp. 157-162 (2008).

17. S. Adeel, I. A. Bhatti, K. EL-Nagar, M. Mohboob Alam, and Nagia Ali, Dyeing Of Cotton Fabric Using UV Irradiated Turmeric (Curcuma longa L) as Natural Dye, Research Journal of Textile and Apparel, 15, pp. 71-76 (2011).

18. S. Adeel, I. A. Bhatti, A. Kausar and E. Osman, Influence of UV radiations on the extraction and dyeing of cotton fabric with Curcuma longa L, Indian Journal of Fibre \& Textile Research, 37 pp. 87-90 (2012).

19. M. N. Zainal, N. Redzuan, M. Fadthul and I. Misna, Brief Review: Cold Plasma, Jurnal Teknologi (Sciences \& Engineering), 74, pp. 57-61 (2015).

20. F. R. Oliveira, A. Zille, F. Steffens and A. P. Souto, Plasma Technology Applied in Textile Industry, Conference Paper, (2014).
21. S. K. Chinnammal and K. V. Arunkumar, Effect of Plasma Treatment on Plain Woven Cotton Fabric, International Journal of Science and Research, 4, pp.83-88 (2012).

22. C. Chen and W. Y. Chang, Antimicrobial activity of cotton fabric pretreated by microwave plasma and dyed with onion skin and onion pulp extractions, Indian Journal of Fibre and Textile Research, 32, pp. 122-125.

23. S. Rattanaphani, M. Chairat, J. B. Bremner and V. Rattanaphani, An adsorption and thermodynamic study of lac dyeing on cotton pretreated with chitosan, Dyes and Pigments, 72, pp.88-96 (2007).

24. T. Kavitha, R. Padmashwini, A. Swarna, V. R. Giridev and R. Neelakandan, Effect of chitosan treatment on the properties of turmeric dyed cotton yarn, Indian Journal of fibre \& Textile Research, 32, pp. 53-56 (2007).

25. M. Verma, S. J. Singh and N. M. Rose, Effect of biopolymer treatment on the dyeing of cotton fabric with natural dye (Onion skin), International Journal of Chemical Studies, 6, pp. 1715-1720 (2018).

26. S. Saxena and A. Raja, Natural Dyes: Sources, Chemistry, Application and Sustainability Issues, Roadmap to Sustainable Textiles and Clothing: Eco-friendly Raw Materials, Technologies, and Processing Methods, S.S. Muthu, Singapore, Springer Singapore pp. 38-88 (2014).

27. W. Sricharussina, P. Ree-iama, W. Phanomchoenga and S. Poolperma, Effect of enzymatic treatment on the dyeing of pineapple leaf fibres with natural dyes, Sciense Asia, 35, pp. 31-36 (2009).

28. P. S. Vankar and R. Shanker, Ecofriendly ultrasonic natural dyeing of cotton fabric with enzyme pretreatments, colorage, 5, pp. 62-69 (2008).

29. P. S. Vankar, J. Srivastava, I. Dumitrescub and A. M. Mocioiu, Enzyme treated dyeing of Cotton, Silk and Wool with Bixa Orellana, Industria textilă, 5, pp. 1-14 (2012). 


\section{أصباغ طبيعية عالية الأداء للألياف السليلوزية ـ الجزء 2}

نانسي الهوارى

قسم الصباغة والطباعة والموا المباد الوسيطة ـ شعبة بحوث الصناعات النسيجية ـ المركز القومي للبحوث ـ

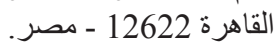

يستعرض هذا الجزء بعض أساسيات التقنيات ، وتطبيقها الواسع ، ويجمع بعض الأبحاث و الدر اسات الجديدة

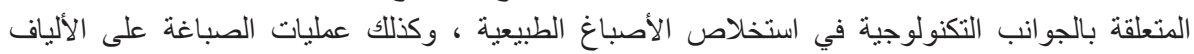

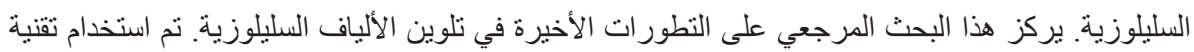

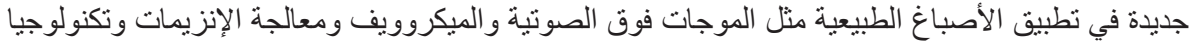

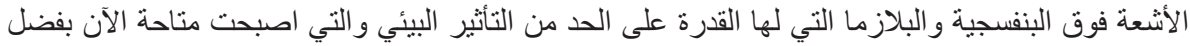
الاستخدام الأقل للطاقة و المياه وكذللك المواد الكيميائية مقارنة بالأساليب التقليدية. 